\title{
Diarios falsos, confesiones fabuladas y rostros hechos a medida: las perfor- mances intimistas de Alan Pauls*
}

Fecha de recepción: 13 de julio de 2020

Fecha de aprobación: 2 de septiembre de 2020

\section{Resumen}

Este trabajo desarrolla una lectura crítica de las incursiones egotistas de Alan Pauls. Su propósito es reflexionar acerca de las estrategias de autofiguración a las que este autor apela para intervenir su material autobiográfico. Para ello, se parte del siguiente supuesto: la narración de eso que llamamos «vida», para un dandi como lo es Pauls, no se deja al arbitrio de los valores que cimentan, en su sentido más vulgar, la práctica de la confidencia (léase búsqueda de autenticidad, franqueza, espontaneidad). Lejos de presentársele como un stock de testimonios fidedignos, la «vida» no es otra cosa para Pauls que pura actuación, montaje, performance. Esta argumentación, dividida en tres partes (la primera centrada en La vida descalzo, la segunda en sus diarios falsos y la tercera en la importancia de la figura paterna), sostiene como hipótesis que los ejercicios confesionales de Alan Pauls, a pesar de las medidas profilácticas que toma para repeler la pretensión de verdad, dejan entrever la persistencia de ciertos impulsos íntimos vinculados con su padre, Axel.

Palabras claves: autofiguración, escrituras íntimas, impostura, infancia, paternidad.

Citar: Rodríguez, E. (2020). Diarios falsos, confesiones fabuladas y rostros hechos a medida: las performances intimistas de Alan Pauls. La Palabra, (39), 19-38. (doi $10.19053 / 01218530 . n 39.2020 .11716$

\section{Emiliano Rodríguez Montiel}

Profesor en Letras por la Universidad Nacional del Litoral y becario doctoral del Conicet por el Instituto de Estudios Críticos en Humanidades (IECH-UNR). Actualmente, se encuentra finalizando el Doctorado en Literatura y Estudios Críticos de la Universidad Nacional de Rosario. De sus trabajos de investigación se destacan: "La literatura como jet lag. Anacronismo y contemporaneidad en Alan Pauls" (CELEHIS, 2018); "Sin meridianos y sin reloj. El mundo feliz de Alan Pauls" (El taco en la brea, 2019) y "Nacer a destiempo: sobre El pudor del pornógrafo, la última novela de Alan Pauls" (Landa, 2020). emiliano.r@ conicet.gov.ar

https://orcid.org/0000-00028050-9151

* Artículo de investigación.

Este artículo forma parte de una tesis doctoral en curso, dirigida por Sandra Contreras y Analía Gerbaudo, la cual estudia la constitución del anacronismo como forma del dandismo contemporáneo en la narrativa de Alan Pauls. 


\section{la palabra}

\section{Fake diaries, made up confessions and bespoke faces: the intimate performances of Alan Pauls}

\section{Abstract}

The aim of this paper is to explore and to analyze the strategies of autofiguration to which Alan Pauls appeals to intervene his autobiographical material in La vida descalzo, travelogues and fake diaries. «Life», for a dandi like him, is not understood as a practice of confidence (that is: a search for authenticity, frankness, spontaneity). «Living», for a cinephile like him, is understood in the same way that the universe of cinema understands it: pure performance, montage, simulation. Even though his confessional exercises are not intented to be true, my hypothesis is that these autobiographical practices hide and indirectly shows certain intimate impulses linked to his father, Axel.

Keywords: Intimate writings, Childhood, Imposture, Autofiguration, Fatherhood

\section{Diários falsos, confissões fabuladas e rostos feitos a medida: as performances intimistas de Alan Pauls}

\section{Resumo}

Este trabalho desenvolve uma leitura crítica das incursões egotistas de Alan Pauls. O propósito principal é refletir acerca das estratégias de autoconfiguração das que este autor faz uso para intervir seu material autobiográfico. Para isso, a análise é feita a partir do seguinte pressuposto: a narração disso que chamamos «vida», para um dândi como Pauls, não é largado ao arbítrio dos valores que cimentam, no seu sentido mais vulgar, a prática da confidencia (leia-se busca da autenticidade, franqueza, espontaneidade). Longe de ser apresentada como um estoque de testemunhas fidedignas, a «vida» não é para Paul outra coisa do que atuação pura, montagem, performance. Esta argumentação, dividida em três partes (a primeira focada em La vida descalzo, a segunda nos seus diários falsos e a terceira na importância da figura paterna) sustenta a hipótese de que os exercícios confessionais de Alan Pauls, apesar das medidas profiláticas que usa para repelir a pretensão de verdade, permitem entrever a persistência de certos impulsos íntimos ligados com o seu pai, Axel.

Palavras-chave: escrituras intimas, infância, impostura, autofiguração, paternidade. 
La experiencia personal de Pauls, la ficción autobiográfica que en el interior de su obra, heterogénea y paulatinamente se viene escribiendo desde 1994 hasta la actualidad, puede clasificarse, abusando de las convenciones genéricas, en cuatro grupos: ejercicios confesionales de largo aliento (contaminados de ensayismo, lo integran $L a$ vida descalzo y Trance), diarios falsos (viciados de ficción, reúne a "Interminable", "Mi vida como hombre", "Un diario (fragmentos)", "Filcar" e "Historia Clínica"), relatos de viajes (publicados, en su mayoría, en suplementos culturales, agrupa a "Viaje al país del taximoto", "Esperando el SNN" y "El futuro anterior"), performances hilarantes (simulando ser parte de una gran comedia de situación, incluye: "Kilometraje ilimitado", "Barbarie celular", "Razones de un suplicio", "Fiestas", "Canas", "Yo como actor" y "Oiropa"), ejercicios confesionales de corto aliento (los más auténticos, como se verá después, de esta «vivioteca»: "Suspenso. Diario de Princeton" y "La casa Berlín. Un blog") y, por último, la serie de novelas que, por su congénito estatuto ficcional, no se trabajarán aquí (Wasabi, Historia del llanto y Noche de Opwijk) ${ }^{1}$.

Si el periodo que va de 1982 hasta 1994 puede sin esfuerzo bautizarse como la «fase introvertida» de su obra, es porque allí -una cuarentena que comprende su primer cuento, "Amor de apariencia" y sus dos primeras novelas, El pudor del pornógrafo y El coloquiotoda comunicación con el exterior (léase referencia histórica, indicación espacio-temporal, alusión autobiográfica, incluso conceptos hoy medulares de su proyecto como «mundo» $\mathrm{y}$ «figura de escritor») está obstruida. Y si, por el contrario, el período que va de 1994 hasta el presente puede apodarse como la «fase extrovertida» de su obra, es porque con la publicación de Wasabi, en efecto, se produce un punto de inflexión. Toda interferencia externa que bajo la lupa hiperliteraria era diagnosticada como un injerto nocivo, propenso a infectar y arruinar sin remedio la castidad de su creación, empieza poco a poco a ser reconsiderada como una opción. El factor desencadenante de esta abertura, de esta disposición a descorrer las cortinas para que otros discursos ingresen a su proceso creativo, no es otro que un contrato. Pues, al igual que sus libros sobre Puig, Borges, Lino Palacio, el diario íntimo, incluso $L a$ vida descalzo y Trance (por no mencionar el sinnúmero de prólogos, traducciones y artículos hechos por encargo), Wasabi se escribe a raíz de una demanda externa:

Yo había sido invitado a Saint-Nazaire a pasar dos meses y el "pago" $[\ldots]$ consistía en un texto de veinte o veinticinco páginas, cuyo único requisito era que mantuviera alguna relación, sin especificar cuál, con el lugar. Apenas llegué, dije que no iba a escribir una línea esos dos meses de la invitación porque no puedo escribir cuando viajo [...] Cuando volví a Buenos Aires comencé a sentirme en deuda con mis anfitriones, y la deuda crecía de un modo inversamente proporcional al poco énfasis que ellos ponían en recordármela. Prácticamente, parecían haber olvidado que yo tenía que escribir un texto en pago a la invitación y yo, cada vez más, estaba obsesionado por ese texto. El conflicto residía en que yo jamás había escrito literatura para pagarle nada a nadie. Frente a esa complicación me dije: ya que estoy en una situación que nunca había atravesado antes, voy hacer algo que tampoco hice antes y que hasta fue contrario a mis principios literarios, voy a trabajar con la experiencia, con la experiencia vivida por mí en esos dos meses. (Tizón, Martini y Pauls, 1995, p. 3)

La violación de este pacto editorial, la transgresión de redoblar el desafío y respetar "en

Tanto los relatos de viajes, como las performances hilarantes y los ejercicios confesionales de corto aliento están reunidos todos, gracias a la selección y edición de Leila Guerrero, en Temas lentos (2012), por lo que sólo será consignado este título en la bibliografía. 
exceso" la cláusula convenida escribiendo no un breve relato anodino, motivado por el «deber ser», sino una novela de casi 160 páginas, promueve en el interior de su política literaria una decisiva transmutación de valores (Tizón et al., 1995, p. 3). Agremiada desde siempre a la consigna "no hay experimentación sin contrato", la escritura paulsiana abandona su condición de caja fuerte blindada para dejarse abastecer por otros insumos, entre ellos los de su propia vida (Pauls, 2012, p. 131).

Ahora bien, lo primero que hay que señalar respecto de esta etapa extrovertida es que, Alberto Giordano - sin duda uno de los peritos más duchos a la hora de escrutar «escrituras íntimas» dentro de la crítica literaria argentina- no le cree nada a Pauls. Al analizar la «pretensión de verdad» de La vida descalzo y "Un diario (fragmentos)" -es decir: cuán corrompido se encuentra el espacio de lo narrado, cuán obturado se halla "el paso de la vida a través de las palabras" (su fórmula insigne), hasta qué punto el orden de lo íntimo es una farsa en estas escenas autobiográficas-, Giordano afirma: «Pauls es quizá el escritor más dotado de su generación [...] y sin embargo a sus textos autobiográficos les falta a veces esa tensión sentimental que es la huella del perseguido encuentro de la literatura con la vida» (2008, p. 32). Para quien el acto confesional es, siguiendo a María Zambrano (1995), «una técnica para el cuidado de sí mismo», en tanto que el que se confiesa busca, antes que la «autocomplacencia narcisista», «una verdad que no humille a la vida, sino que la enamore y transforme»; y para quien lo íntimo es, siguiendo a José Luis Pardo, «nada (nada que se pueda decir, ni siquiera señalar directamente)», y que; sin embargo, «solo resultan auténticas aquellas confesiones que se realizan bajo la presión de algo íntimo en busca de un lenguaje que lo deje sern, las performances intimistas de Pauls no pueden no resultarle el colmo de lo fraudulento (1996, pp. 25-26) ${ }^{2}$. El problema, claro está, es la condición netamente literaria de la confesión paulsiana, el modo en que esta, con sus invocaciones proustianas y sus frases «nacidas para brillar en un ensayo», se ratifica impúdicamente como artimaña, obstruyendo -o directamente anulando- «el paso de la vida de unas palabras que lo reclaman» (Giordano, 2008, p. 32). La diferencia está, en otras palabras, en que lejos de manifestar una necesidad de confesarse, las aventuras narcisistas de Pauls expresan una clara voluntad de novelarse: «Cuando la literatura se afirma como artificio, la vida y la intimidad quedan reducidas a la deprimente condición de materiales para el trabajo» (Giordano, 2008, p. 32) ${ }^{3}$.

Así y todo, ¿qué ocurriría si, a diferencia de Alberto Giordano, que no le cree nada (ni cuando narra la vez que su amigo queda prendado de una mujer avistada en grupo, emulando la escena célebre de $A$ la sombra de las muchachas en flor, ni cuando el niño Pauls se inicia en la lectura abrigándose en la referencia libresca de "Sur le lecture"), lo leyéramos «al pie de la letra»,

\footnotetext{
El texto de María Zambrano (1995) es La confesión: género literario (Madrid: Siruela) y el de José Luis Pardo (1996) es La intimidad (Valencia: Pre-Textos). Cabe mencionar que, además de El giro autobiográfico de Alberto Giordano, en las últimas décadas se ha escrito una copiosa serie de textos críticos sobre el tema de las literaturas del yo, las estrategias de autofiguración y la tríada que articula lo íntimo, lo público y lo privado. Una tendencia que, según el caso, ha tomado diferentes nombres: el giro subjetivo (Sarlo, 2005), la era de la intimidad (Catelli, 2007), la imaginación intimista (Link, 2007), entre otros.

3 Al final de Una posibilidad de vida, el ensayo que antecede y sostiene a El giro autobiográfico, Giordano formula, muy claramente, qué entiende por lo íntimo, diferenciándolo de los otros dos órdenes que le permiten existir, lo privado y lo público: «Lo íntimo no sería tanto "una sutil gradación de lo privado", como una dimensión irrepresentable de la subjetividad, una reserva de indeterminación que escapa a la dialéctica simple en la que lo privado y lo público se oponen para poder complementarse. Tiene que ver con la manifestación de una distancia indecible que impide tanto identificarse, apropiarse sin restos de uno mismo, como ser identificado; una distancia que fuerza la enunciación, hace hablar o escribir, y transforma secretamente cualquier performance autobiográfica en una experiencia de la propia ajenidad. Esta otra versión de la intimidad, que habla de lo íntimamente desconocido que "aparece en el lenguaje como lo que el lenguaje no puede (sino que quiere) decir", está siempre ligada según Pardo al arte de contar la vida, a la posibilidad que tienen las palabras de suspender su significación para transmitir sentimientos y emociones “en estado afectivamente puro"» (2006, p. 207).
} 
es decir, cayendo en su trampa, entregándonos al poder de su sugestión, solidarizándonos con su empresa autofigurativa? Trocar en favorables las postulaciones adversas de Giordano (en el que él escribe "ejercicio retórico desencantador", leer sesgadamente «encantador»; donde él escribe "deprimente", leer panglosianamente «fructuoso», y así), permitiría ingresar y recorrer en calidad de intrusos el interior de la sastrería de Pauls. Esa misma en la que, sirviéndose de diferentes estrategias, desbarata su material autobiográfico en vista de exhibirlo públicamente como máscara, traje, performance. De lo que se trata, dicho de otra manera, es de leer sus incursiones egotistas no como un lector de escrituras íntimas, "que siempre espera más", no como un lector de lo confesional, que se enfrenta a la difícil tarea de examinar los modos en que «un sujeto se confronta con la necesidad de transformarse»; sino, más modestamente, como un lector de ficción, esto es, adjudicándole a aquello que se escribe una inequívoca dignidad literaria (Giordano, 2008, pp. 32-33).

De allí, que los problemas a explorar no sean -en principio, $y$ solo en principio como se verá después, cuando este razonamiento vuelva sobre sus pasos para objetarse- los suministra- dos por las nociones de lo íntimo y lo verdadero. Antes que proveer la dosis de "intensidad dramática" que espera recibir un lector que se interesa por las resonancias auténticas del cruce entre literatura y vida, lejos de reconocerse como un "acto de desprendimiento y modificación de sí mismo", la confesión en este universo se concibe, por el contrario, como un espacio de experimentación regulado por los principios y los procedimientos de la ficción (Giordano, 2008, pp. 25-26). ¿Qué vida, qué rostro, qué valores y qué poses son las que inventa para sí, Pauls, en sus performances intimistas? ¿Cuál es el móvil principal de esta autofabricación y cuáles son sus efectos, los premeditados y los que no? ¿Cuál es el precio que paga Pauls por no abandonar nunca el discurso literario y ensayístico al confesarse? ¿Qué réditos y qué descuidos o pasos en falso pueden divisarse en su carrera de impostor? ¿Qué traje le queda mejor y cuáles son aquellos momentos en los que, por una desafortunada combinación de prendas, sus artilugios quedan expuestos al descrédito público, el mayor de los agravios para un dandy? El desarrollo que se despliega a continuación intenta, siguiendo la clasificación bibliográfica convenida al principio del apartado, responder estas preguntas ${ }^{4}$.
Primer acto: La vida descalzo

Definido por Daniel Link (2006) como un «libro exquisito» por llevar a la frase «a niveles desconocidos de elegancia, musicalidad y proliferación narrativa» (párr. 1); interpretado por Selma Cohen (2012, p. 72) como un tratado "paisaje-concepto" por escoger, al igual que el Facundo de Sarmiento, un territorio para «desarrollar un proyecto de escritura» (la playa); fichado por Teresa Orecchia Havas (2013, p. 10) como "un texto-bisagra" entre $\mathrm{El}$ pasado y el tríptico de las Historias e inventariado; por Graciela Villanueva (2019), como un mito más de las Mitologías barthesianas por «describrir y deconstruir los estereotipos asociados a la playa en la sociedad contemporánea» (p. 2), La vida descalzo es, sin lugar a dudas, el producto más ecléctico y peculiar de la tienda paulsiana. Singular o distintivo, en todo caso, porque esta mezcla de ensayo, ficción y autobiografía - «la mezcla de estos tiempos», el decir de Alberto Giordano-, incluye dos materiales hasta la fecha inéditos en su mesa de trabajo: diez fotografías incautadas directamente de su álbum familiar y diez narraciones autobiográficas de su infancia y juventud (Giordano, 2008, p. 37). «Diez», parece ser entonces, el

Por cuestiones de extensión y con el objeto de favorecer una lectura exhaustiva de los demás materiales que conforman el corpus, Trance no se incluye en el análisis. Por otra parte, cabe mencionar que, este trabajo parte del supuesto de considerar la obra de Alan Pauls como forma del dandismo contemporáneo (ver Rodríguez Montiel, 2019). 
código genético que describe la fisonomía de este texto nacido por encargo de la editorial Sudamericana para la colección In Situ. Diez son los apartados, todos sin título y separados por una foto pequeña, en blanco y negro, del niño Pauls veraneando, y diez son los sentidos que se exploran, desde diferentes aristas y saberes, exprimiendo o directamente agotando todo su volumen semántico, del objeto «playa».

Imagen » concepto « confesión: sobre estos tres componentes se apoya y levanta La vida descal$z o$. Un trípode misceláneo cuya feliz simbiosis se explica al examinar la exclusiva función y el lugar diferente que ocupa cada uno de estos elementos en el entramado textual. En calidad de paratextos, orbitando por fuera del centro que les da sentido, las fotografías auguran, en primera instancia, la noción general de la playa que palpita tácitamente en el fondo del libro: como un árbol pudoroso que solo desviste sus últimas y más altas ramificaciones, las diez acepciones germinan de este tronco a la vez invisible e indeleble, solo posible de vislumbrar en la reverberación de estas imágenes-medianeras. Las confesiones, en segundo lugar, sirven en todos los casos de ejemplo -en el sentido más pedagógico del término- de estas conceptualizaciones: hacen valer la estirpe etimológica de su antepasado, el exemplum, las vivencias ilustran y actúan las ideas, le asignan un cuerpo y una historia, un nombre y una voz, al ejercicio ensayístico. Se observa, así, cómo la imagen y la confesión gozan de una posición subsidiaria, no protagónica, con respecto al concepto, el cual, apoderado absoluto de este triángulo solidario, orquesta a su necesidad y placer los aportes de los demás contribuyentes. La radiografía más ad hoc de La vida descalzo sería, por esta razón, aquella que incursionase nivel por nivel, piso por piso, este empalme diegético entre ilustración, explicación y narración.

¿Qué tipo de niño es este que se nos revela en el blanco y negro de varias de las películas que se mencionan aquí, como La aventura de Antonioni y De aquí a la eternidad de Zinnemann? ¿Qué sentidos verbaliza su pose ermitaña, signada por el olvido hacia la cámara, una faz contemplativa y un cuerpo más bien retraído? ¿Qué nos confiesa la absoluta castidad de su ambiente, en el que prácticamente no hay nada salvo unas terribles ganas de estar solo? «Me da la impresión -cuenta Pauls frente a un Guebel en off- de que muy rápido yo me corté solo, como quien dice. Elegí una especie de experiencia solitaria, relativamente autista digamos, o de un autismo razonable si se quiere, para que no me hincharan las pelotas» (Montes-Bradley y Guebel, 2005). A diferencia de las playas «sepultadas bajo el peso de la especulación inmobiliaria, el frenesí urbanizador, el boom del turismo de masas y una cultura del ocio hegemonizada por el consumo» (Pauls, 2006a, p.23) - el ecosistema distintivo de la costa argentina en verano, ese mismo que, poblado de familias, sombrillas, heladeros, guardavidas y un sinfín de juegos y rituales, Mariano Llinás retrata etnográficamente en su documental Balnearios-; y en consonancia, por el contrario, con playas menos espectaculares y más deshabitadas, menos estridentes y más circunspectas - como las de Dinard y Mimizan, las dos localidades francesas donde transcurren otros dos dramas aludidos aquí: Cuento de verano de Éric Rohmer y Sobre la arena de François Ozon, respectivamente-. La playa del niño Pauls es, ante todo, virgen, diáfana, insonora o, en mejores términos: una hoja en blanco disponible para la ficción.

Porque, más allá de las variadas acepciones que moran en cada apartado - a saber, la playa como: a) bóveda onírica; b) pantalla en blanco símil a la del autocine; c) paraíso anticapitalista y contracultural en la década de 1960; d) «infierno superpoblado con vista al mar» en el presente; e) paisaje de restos y escombros que reúne, en la fisonomía anacrónica de la arena, «lo que estuvo antes y lo que vino después»; f) territorio salvaje, sin monitoreo, proclive a la inva- 
sión y a servir como campo de batalla; g) zona erógena, idónea para funcionar como «estímulo escenográfico» en la noche; $h$ ) esfera comunitaria que democratiza el cuerpo, la desnudez y la belleza gracias a la vida «sin autoridad» que propone; i) objeto de pensamiento literario e intelectual cuando se la deprime, es decir, cuando se la habita «fuera de temporada»; j) experiencia clasicista ligada menos al contacto con lo Húmedo que al roce con lo Seco: «seca la arena, secos los pies, secos los tablones de madera»-, un sentido general patrulla y vertebra todo el libro (Pauls, 2006a, pp. 11, 23, 37, 50, 70, 86, 94, 117). Una idea matriz, graficada inmejorablemente en las fotografías arriba adjuntadas, que interpela no lo que la playa es, abrazando vaya a saber qué sueño de objetividad, sino lo que el niño Pauls -ese «niño alemán rubio de publicidad nazi»- puede hacer con ella: imaginar, figurar, suscitar, inspirar, alucinar y proyectar «las imágenes más arbitrarias», los sueños más cinematográficos, los deseos «más felices» (Pauls, 2006a, pp. 19, 24, 106, 111). La playa, en otras palabras, es una potencia, un "territorio libre de imágenes" o "una superficie neutra y absorbente" -el vocabulario es infinito-, propicia para ejercitar, sostener y terminar de depurar algo que empieza muy lejos de allí, al resguardo del sol, el viento y el agua, con luz artificial y custodiado de cua- tro paredes: el vínculo con la ficción (Pauls, 2006a, pp. 11, 24). Pues, además de caminar sobre los hombros de su padre por la peatonal de Villa Gesell, además de jugar al fútbol con un Luizinho habilidoso en Río de Janeiro, además, incluso, de «emprender durante el día las aventuras clásicas de la playa (médanos, bosques, muelle, mar, y el desafío máximo, ¡la caminata hasta Cariló!)», lo que el niño Pauls hace en este espacio-pantalla es continuar con los ritos que devotamente profesa en las demás estaciones del año: ir al cine (Pauls, 2006a, pp. $9,16,61,63,85)$, ir a la librería (pp. 28, 30), leer (pp. 123-125), soñar (pp. 9-12).

No cualquier infancia se pergeña, en este sentido, en la playa de La vida descalzo. Haciendo suya la consigna del Barthes por Barthes («Todo esto debe ser considerado como dicho por un personaje de novela»), recreando hasta el más mínimo detalle el gesto teatral del teórico francés al decir "yo" ("la gran impostura" barthesiana: apoderarse de la instancia de enunciación para usufructuarla menos como "una fuente única" y estable que como "una condición de posibilidad, un marco"). Pauls compone sobre las playas de su vida una niñez novelesca que estetiza diligentemente el temple y el espíritu, léase la ensoñación, el autismo y la bibliofilia, de la escuela al comienzo apuntada (Pauls, 2018, p. 11).
Una puesta en escena, dicho de otra manera, cuya preparación y ejecución obedece las directrices del biografema, la cadena de montaje de la factoría Barthes para ensamblar literatura y vida. «Si yo fuera escritor -confiesa en su célebre pasaje de 1971, hoy vuelto definición- cómo me gustaría que mi vida se redujese, gracias a un biógrafo amistoso y sin prejuicios, a unos detalles, a unos gustos, a algunas inflexiones: podríamos decir "biografemas", cuya distinción y movilidad podrían viajar libres de cualquier destino» (Pauls, 2018, p. 15). Sopesada primero con otros (Sade, Fourier, Loyola), para luego ser directamente perpetrada sobre sí mismo (Barthes por Barthes), esta técnica de corte y confección autobiográfica apuesta, en palabras del propio Pauls, a

retratar un sujeto sin narrarlo, sin disciplinar sus pormenores de vida con una línea de tiempo, más bien sorprendiéndolo en coyunturas caprichosas ('momentos') y rasgos puntuales [...] que relanzan el sentido de una vida menos por lo que la represen$\tan$ que por el modo en que la novelan. (2018, p. 12)

La experiencia y la ficción convergen, de esta forma, arrimándose una a la otra para frotarse mutuamente, en una solidaridad profunda, a la vez íntima y fecunda. Vida estetizada, ficción autobiográfica, novela biografema. Sea como sea, invocada 
o catalogada La vida descalzo, el rol protagónico de estos "bloquecitos de vida ya encuadrados, escenificados, montados, orquestados mediante aires, actitudes, maneras, posturas que funcionan de algún modo como artificio", lo ostenta un niño de clase media ilustrada en torno al cual se nuclean -además de la faceta lectora explorada al inicio de este trabajo- dos rostros en apariencia antagónicos: el del cinéfilo y el idiota (Pauls, 2012, p. 174). Como un número de clown que incluye varios cambios de vestuario, la performance estival y sesentera del niño Pauls se desdobla, en efecto, en dos papeles bien diferenciados: el primero, oficiando de auxiliar del recuerdo en la tarea de ilustrar el concepto, exhuma la videoteca extranjera que frecuenta el adulto que escribe; el segundo, especie de contracara o lado B de esta pose avezada y sin rubores, teatraliza una estupidez fingida que trasluce hasta qué punto el ridículo, si se lo entrecomilla en el atelier dandi, puede convertirse en un valor y en un campo de acción para la impostura 5 .

Varios son los cines que este infante visita junto con su hermano (el Roxy, el Atlantic, el autocine de Villa Gesell), y muchos más son los títulos que la sala de La vida descalzo regenteada ya por un Pauls adulto, anuncia en su cartelera (a los ya citados se le agregan, entre muchos otros: Targets de Peter Bogdanovich, Chitty Chitty Bang Bang de Ken Hughes, El satánico Dr. No y De Rusia con amor de Terence Young, La pandilla salvaje de Sam Peckinpah y La strada de Fellini). Desempeñando el papel de recurso, evidencia, combustible, horma para la identificación o mímesis, este stock de ficciones asiste a la narración autobiográfica en su labor de tonificar el ejercicio ensayístico. Así, por mencionar solo algunos ejemplos, el film de Ozon fortalece la idea de la playa como espacio lampiño y raso, desnudo y transparente ("quizás nadie en el cine haya trabajado tan sutil y radicalmente esa condición hipervisible de la playa como François Ozon en la primera media hora de Bajo la arena"); las ficciones veraniegas de Éric Rohmer, Cuento de verano, Pauline à la plage $\mathrm{y}$ El rayo verde, pregonan la potencia erótica de la playa, esa que solo se activa en ausencia, «cuando queda atrás, cuando se la olvida, cuando se la tragan la noche o el día de lluvia»; Julia de Fred Zinnemann promueve un modelo de playa invernal, inhóspita, "seria", literaria o intelectual, ideal para profesar un romanticismo sacrificial (Pauls, 2006a, pp. 39 68-69, 97-98).
Ahora bien, si esta cinefilia prefigura evoca al Pauls crítico -ese mismo que, sentado en un sofá cuadrado de cuero rojo, encamisado iy hasta una vez trajeado! presentó durante años una película indie para el ciclo Primer plano I.sat-, una vivencia algo extraviada al final del cuarto apartado viene a echar por tierra todo este aplomo y esta erudición, toda esta solidez y autoconfianza a la hora de predicar sobre sí mismo. $\mathrm{O}$, mejor valdría decir, viene a subrayar y a vigorizar, gracias a la magia del contrapunto, esta imagen:

Yo intenté alguna vez ser un idiota y fracasé. Estaba con un amigo en Mar del Plata, en Punta Mogotes, jugando en la arena dura con una de esas pelotas inflables que la brisa más tímida vapulea como quiere. Acalorados, no sé quién de los dos propuso mudarnos al mar con la pelota. A los cuatro minutos la pelota flotaba sin control rumbo al horizonte, hacia ese Otro Lado del Mar que de chico todos los adultos, no sé si para disparar mi imaginación o para aterrarme, llamaban genéricamente «África», y mi amigo y yo, sorprendidos por la jugarreta súbita que el fondo arenoso acababa de hacerles a nuestros pies, gritábamos, tragábamos agua, tosíamos, nos deshacíamos en brazadas inútiles, hasta

\footnotetext{
Toda vez que en el curso de este trabajo se conjure la noción de «dandismo» se estará haciendo subrepticiamente referencia al modo en el propio Pauls entiende al dandismo hoy: una sensibilidad devenida ética o, directamente, una actitud, localizable en no pocas operaciones artísticas del siglo veinte y de la contemporaneidad promovidas por la fuerza de la inadecuación (respecto a esto ver: Pauls, 2013, pp. 9-24; Rodríguez Montiel, 2019).
} 
que por fin, ya en el límite, arriados, supongo, por una olita misericordiosa, porque librados a nuestra propia idoneidad de nadadores no habríamos permanecido a flote ni veinte segundos y por otra parte nadie se había acercado a socorrernos, encontramos el camino de regreso a la orilla, tierra firme pero humillante donde esperaba una pareja de bañeros parados frente al mar, las manos cruzadas a la espalda, los silbatos intactos colgándoles del cuello, tan crueles que mientras pasábamos a su lado exhaustos, arrastrándonos como podíamos sobre nuestras pobres piernas acalambradas, en vez de confortarnos o reconvenirnos, se limitaron a mantener la vista fija en el horizonte y uno, sonriendo, señaló con un dedo la pelota que ya se perdía a lo lejos. (Pauls, 2006a, pp. 43-44)

Podría haber pasado desapercibida, como una anécdota más de las muchas que ornamentan este ensayo, sino fuera porque este gesto de hacerse el tonto -este acto de confesar una torpeza, testimoniar un ridículo, reseñar sus pasos en falso frente al mundo- puede encontrarse desperdigado en varios momentos de su producción crítica. Como si no pudiera contenerse, sugestionado vaya uno a saber por cuál sortilegio cómico (¿el deseo de ser un crítico gracioso?, ¿un intelectual hilarante?, ¿el héroe conciliador que ponga punto final a la grieta que divide mundo y libros, cultura letrada y cultura popular, sofisticación y trivialidad?), Pauls abandona la seguridad de la biblioteca para cruzar la verja que lo separa del mundo exterior. Ese sobre el que aparentemente, según veremos a continuación, no sabe nada, es un inexperto, un mono con navaja, un extraterrestre que acaba de bajar de Marte, un recién nacido abandonado, sin más madre y abrigo que su propia estupidez.

Episodio 1: sale a pasear en su Renault 18 por la península mexicana de Yucatán «cuando un grupo de niños con poca puntería» lo apedrea sorpresivamente a la salida de Cancún (Pauls, 2012, p. 285); episodio 2: después de filmar "una escaramuza erótica" con Martina Guzmán, su coprotagonista de La vida nueva (2011), se queda dormido en el set de filmación: «Cuando desperté no quedaba nada ni nadie. Luces, trípodes, cables, generadores, todo se habían llevado en silencio [...] no me perturbó verme en calzoncillos y bata, solo, sentada en esa silla alta y severa» (p. 336); episodio 3: en la cola del cajero de un supermercado en Berlín, «un alemán muy blanco, de barba canosa y gorra con visera» le recrimina «rumiando con encono» que ese melón que ha quedado huérfano en la cinta es suyo (p. 143); episodio 4: días más tarde, en ese mismo supermercado (Kaiser's), «un ciruja de unos cincuenta años» le pide 50 centavos para pagar «dos botellas chicas de cerveza» con la promesa de que, cuando se vuelvan a ver, él se los devolverá. Accede y al salir ve cómo ese mismo ciruja, con las dos botellas de cerveza bajo una axila, «regatea el precio de un chaleco de cuero sin mangas con la duela de la tienda de ropa de segunda mano de la esquina» (p. 151); episodio 5: sin saber cómo hacer andar la televisión mira, una y otra vez en su «departamentito harlem-columbia» de Princeton, «un único capítulo de Saturday night live (mayo 2009, creo), el único archivo al que conseguimos entrar, con Justin Timberlake de anfitrión» (p. 320); episodio 6: camino a Machu Pichu, en una posada en Ollantaytambo, una pareja de huéspedes suecos lo ayudan, «con una paciencia infinita», a desagotar su cámara digital y copiar sus centenares de fotos en un $C D-« i c o m p r a d o$ por ellos!»- mientas él contempla absorto, «como los simios el monolito de 2001» (p. 120); episodio 7: a principios de la década de 1980, durante la Guerra de Malvinas, confunde el «rumor de los motores» de un camión de recolector de basura con el estrépito de un bombardeo inglés sobre su departamento en calle Belgrano: «Los aviones parecían estar abajo, arriba, a los costados del departamento [...] Escondiéndonos debajo de las sábanas nos abrazamos y empezamos a despedirnos: "Te quiero, te amo", nos decíamos 
al oído, "si no fuera por estos hijos de puta", hubiéramos llegado a viejos y juntos» (1993, p. 470). Y sigue.

¿Cómo leer estas escenas, estos incidentes que de literatura no tienen nada salvo el afán por fabularse incapaz, ignorante, idiota? El tópico del artista que «no sabe vivir», que trunca sostenidamente su cotidianeidad por desconocer las leyes de lo obvio, lo evidente, lo consabido por todos -ese mismo que César Aira retrata con maestría al inicio de Cumpleaños: «poco a poco se me fue haciendo patente lo monstruoso de mi ignorancia $[\ldots][\mathrm{Y}]$ que yo me considerara un intelectual, un hombre cultivado, curioso e inteligente, hacía más risueña la broma»-, parece ser una vía más que oportuna para leer este gesto (2001, p. 11). Habría que señalar, no obstante, que si el escritor aireano busca al menos atenuar su incompetencia improvisando una coartada -«El único miserable consuelo que podía darme era que estas distracciones fueran el precio con el que pagaba mi atención a otras cuestiones»-, a Pauls, por el contrario, su patetismo parece gustarle (Aira, 2001, p. 13). Gustarle, como parece gustarle el gen del fracaso que liga a Erik Lönnrot, Juan Dahlmann, John Wilkins, Nils Runeberg, Pierre Menard e Ireneo Funes, todos «sabios idiotas, talentos desperdiciados, artistas fanáticos del error y la insensatez»
(Pauls, 2000, p. 147). Gustarle, como parece gustarle el Crack$U p$ de Francis Scott Fitzgerald, «el más grande pensador» del fracaso, «su redentor y sobre todo su apóstol, un propagandista del derrumbe» que exploró a través de su literatura y su vida «las formas múltiples de perderlo todo: fortunas, juventud, belleza, talento, notoriedad, potencia» (Pauls, 2011b, p. 1011). Gustarle, como parece gustarle, en definitiva, el adn de todos sus personajes, una familia poblada de criaturas necias que desconocen el valor de la ubicuidad, la adecuación, la perspicacia, la oportunidad, el éxito. Tan solo atisbar el derrotero del infeliz de Rímini en El pasado o de su «alter-ego» en Wasabi, para darnos cuenta de hasta qué punto la ineptitud, cuando se la combina con la errancia y el absurdo, el ridículo y el más acentuado infortunio (todas propiedades de su recurso cómico favorito: el gag), es central en la imaginación paulsiana.

Con todo, ¿qué ocurre cuando el chiste sale mal, cuando el golpe de efecto no es el esperado, cuando culpa de una contraindicación no leída los componentes que se intentan integrar se inflaman, desencadenando la mayor de las desgracias para un dandy, la reprobación pública? Si la galaxia Pauls está habitada en su mayoría por asociaciones arbitrarias, dichosas por su insospechada correspondencia, también lo está por articulacio- nes menos felices, desestimadas por defectuosas, pero imposibles de descartar del todo. Como los almuerzos de Borges con Rafael Videla y Augusto Pinochet, por citar un desliz imborrable para el imaginario pop de la literatura argentina. Los reveses de Pauls, si bien más modestos e indefensos que los anteriores, son pequeños remanentes, tropiezos arriba del escenario, despistes que permanecerán para siempre indelebles en su papelera de reciclaje. El abandonar la biblioteca para ponerse a hablar de otra cosa, el optar por renunciar a la profilaxis que escuda su palabra tiene, según lo deja en claro cada tanto el prontuario de sus intervenciones no literarias, un costo fijo: ponerse a disposición de la doxa, esto es, ofrecerse como carne de cañón para que otros saberes -otros lectores, oyentes, diletantes, fisgones y opinólogos seriales- lo interpelen, lo saboteen, lo escrachen. De allí que, al contar en su columna de Página/12 cómo MercadoLibre le suspendió la cuenta por haber recibido dos calificaciones negativas de sus potenciales vendedores y su nombre haya ido a parar, sin más, a la guillotina virtual de Twitter:

Primera vez en la vida que me echan de un lugar. Lo que en más de cincuenta años nunca hicieron mi familia, ni mi club, ni mis patrones, ni las parejas que tuve, ni los lugares públicos que frecuenté, ni las autoridades del país en 
el que vivo y los que visité alguna vez, lo hizo por fin mercadolibre. (Pauls, 2011c, párr. 1)

Como un reo expuesto al oprobio público en plena Edad Media, clamores del tipo «soy un paria de un mundo extraño, el de mercadolibre» o «solo esPERO QUE EL ANTecedente no afecte futuras visas a Estados Unidos o posibles créditos bancarios» le valieron, inexorablemente, ser objeto de escarnio ese domingo 2 de octubre (2011c, párr. 9-10). Incluso varios portales informativos, entre ellos uno exclusivamente dedicado a proteger los derechos del consumidor, favorecieron a mantener en pie, un día después, el trending topic abanderado con el hashtag \#UnabiciparaAlanPauls. El percance, por lo demás, está lleno de curiosidades: MercadoLibre se contactó con él para solucionar el inconveniente, un anónimo detractor abrió una cuenta falsa en Twitter con su nombre (hoy suspendida gracias a la intervención del propio Pauls, fastidiado frente a la pereza inspectora de algunos medios, como Intrusos y La vanguardia, que estimaron y reprodujeron algunos tuits como información fehaciente), y hace apenas unos meses, al cumplirse los 9 años, se celebró en la red social el aniversario del incidente.

Y hay más. En septiembre de 2018, Matías Falco lo entrevista para Infobae a propósito de Trance y, al final, cuando la conversación muestra signos ya de languidez y vencimiento, Pauls le regala a su interlocutor el título de la nota: «No soporto el lenguaje inclusivo, van a pasar sobre mi cadáver antes de que yo diga todes» (Falco, 2018). Más allá de la malicia sensacionalista que pueda haber sufrido este exabrupto en el proceso de edición, el acto - ¿audaz? ¿sincero? ¿necesario?- de posicionarse en un más acá de las almas conservadoras y en un más allá de la corrección política, lo hizo merecedor, otra vez, de estar en boca de todos, o por lo menos de todos aquellos a los que el tema-léase twitteros, periodistas, escritores, panelistas de radio y televisión, docentes, no docentes, militantes y detractores de la causa, aficionados anónimos al deporte del escrache- los cautivó en mayor o menor medida esa semana (Falco, 2018).

Todo parece conducir, al menos en este punto, a la pregunta por la recepción, por ese lector posible que el Pauls periodístico y pop tiene en mente a la hora de incursionar por revistas como SoHo (revista colombiana de 'entretenimiento' masculino) o Marie-Claire (revista francesa de 'entretenimiento' femenino), en temas como sus canas, los antitranspirantes que usa o los hoteles alojamiento que ha visitado (Pauls, 2012, pp. 285307). Quizás, en esta aventura extraliteraria y de apetito puigiano, el lector sea solo parte del paisaje, especie de entidad abstracta o incorpórea que asiste insonoramente a las variadas formas en las que un escritor, al salir de la jaula versada que lo tiene sosegado, se deprava a sí mismo por carriles ignotos. El público como decorado, sonido ambiente, patio de butacas silenciosas, puesto únicamente allí para funcionar tal y como lo requiere un dandy: como eco, output, cámara Gesell ${ }^{6}$.

\section{Segundo acto: Pauls diaris- ta}

Lejos de ser el registro mundano, fehaciente y testamentario del flujo de una vida - «una práctica espontánea de la franqueza y apertura total del corazón»-, el género «diario»se concibe dentro de este universo como un espacio de experimentación regulado por los prin-

\footnotetext{
O al menos así lo entiende el propio autor, hace casi ya veinte años, ante Martín Kohan y Alejandra Laera, lo asevera: «En un momento, yo tenía la ilusión de que el periodismo podía hacer presente la idea del público, que para mí siempre es completamente fantasmal. Después me di cuenta de que el público puede ser tan fantasmal en el periodismo como lo es en la literatura. El tipo de respuesta con el que me encontré escribiendo en el diario es tan errático y está tan desfigurado por los malentendidos como el tipo de respuesta que tengo cuando escribo literatura o ensayos. Es más, las pocas veces que hubo alguna respuesta, fue siempre por cosas que no tuvieron que ver ni con la cultura ni con la literatura, sino cuando accedí a opinar sobre Maradona, Charly García o los travestis» (Kohan y Laera, 2001, p. 67).
} 
cipios y los procedimientos de la ficción (Pauls, 1996, p. 6). A cierta versión primigenia de la historicidad del género (18001860) que presupone «una absoluta indiferencia por el destino literario», se antepone otra, menos transparente y más abigarrada, menos fidedigna y más estetizada, que pervierte las banderas convencionales del género (la inmediatez de la primera persona, la veracidad de la experiencia y el respeto hacia el calendario, entre otras) en beneficio de un proyecto específico: «adjudicarle a aquello que se escribe una inequívoca dignidad literaria» (Giordano, 2008, p. 137). No se trata, ahora bien, de reconocer en esta acepción la condición paradojal que desde hace ya una década -en el amplio marco de los estudios sobre las escrituras del yo- se comprende como intrínseca, a saber: el carácter híbrido que porta todo diario de escritor, producto del juego sin frontera que propone entre literatura y vida (Domínguez 2012, p. 99; Giordano, 2017, p. 709). Se trata, más bien, de una treta: en el periodo que va de 2002 al 2011 , Pauls escribe un puñado de microrrelatos en forma de diario íntimo con el único propósito de -como buen embaucador y artero que es- salir del paso, cumplir con una obligación, sobrevivir al calendario más o menos exigente de exposiciones a las que un escritor como él, que no evade las tablas como su coetáneo Aira, se somete regularmente:

empecé a escribir diarios falsos. Fue una astucia que se me ocurrió en un momento en que me invitaban a participar en congresos, en coloquios, en general más bien académicos o académicos con escritores. Me daban un tema y me era cada vez más difícil responder al tema, supongo porque me alejaba cada vez más del mundo académico, pero es un mundo con el cual no quiero perder la relación porque hay una interlocución que me interesa y hay allí algo más crítico sobre la literatura. Y entonces en un momento descubrí que mi salvación era la forma del diario íntimo. Fue una decisión: "a cada congreso, a cada coloquio que me inviten para participar con una ponencia sobre un tema $\mathrm{X}$, responderé con un diario íntimo". Y la puse en práctica, más de 5 veces. Y lo que me permitía el diario íntimo obviamente era poder navegar -de un modo completamente caprichoso, arbitrario, y a la vez legitimado por un género- por todas esas zonas en las que me gusta navegar para mi trabajo, y sin tener que preocuparme por la jerarquía de esa zona, sin tener que preocuparme demasiado por la articulación de esas partes, como si empezara a trabajar con un principio de montaje. Ahí podía ser escritor y responder al tema del coloquio. Entonces el diario era a la vez pertinente y completamente caprichoso. Era la aportación que yo hacía. Y el diario me parecía un buen género para definir una cierta manera que tengo de relacionarme con la literatura, que es una relación de lector, de crítico, de ensayista, de escritor de ficción, etc. $\mathrm{Y}$ encima podía agregar cosas de mi vida personal muy deformadas, muy, muy deformadas, con lo cual se convertía en un monólogo de comedia. (Laurent, 2010, pp. 120-121)

Apiñar, como lo hace desvergonzadamente este apartado, los términos «Pauls» $\mathbf{y}$ «diarista»; amontonar, como un cartel publicitario ávido de sugestión e impacto, dos palabras en principio prometedoras (o al menos así las acogen los lectores de Cómo se escribe un diario intimo, el ensayo donde el susodicho, valiéndose de mini-entradas menos introductorias que iluminadoras, prologa los diarios de Kafka, Musil, Pavese y Barthes, entre otros), resulta, a la luz de lo recién citado, una completa y vil estafa. Nada más apócrifo que los diarios apócrifos de Alan Pauls: uno ingresa, famélico de confesiones indiscretas, diatribas contra otros escritores, chismes lascivos de la escena literaria local y, por qué no, traumas familiares irresolutos (¿todo lo que el Borges de Bioy nos da?), y lo que recibe en cambio no es más que un show de stand up compuesto, en su mayoría, por reversiones de personajes ya habitué de este 
trabajo, como el idiota, el neófito, el perdido. Él, que se ha declarado infinidades de veces groupie de Seinfeld («Soy el más grande erudito en Seinfeld que debe haber, o quedar, sobre el planeta. Voy a fiestas y reuniones y no hago otra cosa que contar el argumento y las vueltas de tuerca y los chistes del capítulo que vi la noche anterior») (Pauls, 2011a, párr. 5); él, que a lo largo de los cinco años que duró el proceso de escritura de El pasado no hizo otra cosa que mirar, por la noche, totalmente exhausto y derribado por el lenguaje, un par de capítulos de la sitcom antes de irse a dormir («Seinfeld forma parte de mi vida, me devolvió como un fanatismo adolescente. Me produjo el mismo efecto que En busca del tiempo perdido»), hace suya la lógica de la serie, se la expropia, como quien dice, para sortear sus compromisos como escritor (Pérez Zabala, 2017, párr. 31). De allí que, sus diarios sean un elogio de lo menor, de lo que de patético, hilarante y absurdo tiene la vida de un escritor cuando no escribe y decide hacer o decir otra cosa, como intentar tener vida social y fracasar en el intento ( $« I r$ a una reunión y cambiar de interlocutor. Qué tormento indecible [...] Tardo tanto en cambiar de conversación. Es tanto lo que tengo que saber del otro para poder dirigirle la palabra, y tanto, también, lo que tengo que olvidar para hacer lugar a lo nuevo...»), probar cambiar de identidad genérica («Cansado de ser hombre. ¿Habrá una chica en mi cuerpo? No sé. Quisiera estar abierto a todas las posibilidades»), caminar por su ciudad natal y extraviarse sin remedio al llegar a Otamendi y Rivadavia («¿Cuántas veces pasé por allí? ¿Cincuenta? ¿Cien? Y sin embargo no falla: llego hasta ahí, donde la calle se interrumpe $[. .$.$] y ya no dis-$ tingo la derecha de la izquierda. Estoy perdido. Perdido como en una selva en medio de la ciudad donde vivo hace cuarenta y cinco años»), comer comida para perros ( Me da hambre. En la heladera no hay nada. Debajo de la pileta de lavar, escondida tras el lavarropas, descubro -menos mal- una bolsa de alimento balanceado para perros. Es para cachorros. Espero que no me caiga mal. ¿Tuvimos alguna vez un perro, nosotros?»), ser un auténtico naif -por no decir niño, ingenuo, iluso- en materia amorosa («Completamente desvelado. Busco a mi mujer por toda la casa; no está en ningún lado, no dejó ninguna nota, nada [...] Suena el teléfono: es mi mujer. Hay mucho ruido en la línea. Me dice que no me preocupe, que está estudiando en lo de una compañera de facultad $[\ldots]$ Ni siquiera sabía que mi mujer estudiara») (Pauls, 2002, p. 45; 2006b, p. 103; 2011a).

Así y todo, una serie de entradas se resisten a ser catalogadas como parte de esta biósfera có- mica, impostora y dandi. Desparramadas por "Mi vida como hombre" (2006b) y "Un diario (fragmentos)" (2006c), estas escenas arman, al congregarse en la lectura, un pequeño pelotón autobiográfico cuya mayor victoria y motivo de orgullo es la de ganarle, no sin esfuerzo, la partida a la ficción. No es que no pueda reconocerse en estos pasajes el artificio de la fabulación, el manoseo autoral, las restricciones a la que se subyuga el orden de lo confesional, al osar atravesar el camino de las palabras. Todo eso está muy bien cimentado y, sin embargo, al transitar por sus veredas es tal lo mucho que esta vez nos podemos acercar, en tanto lectores, a eso que mal llamamos privacidad, que dejarlas caer sin más a la fosa común de lo público (léase los fuegos artificiales que hemos estado avistando hasta el momento), sería precipitado o lisa y llanamente un error. Nos referimos, claro está, a los momentos en los que Pauls se figura como padre: «Rita» es, gracias a su calidad de hija, la mirilla que nos permite vislumbrar - como intrusos, espías, voyeurs, como un personaje más de sus ficciones de incógnito- el otro lado pauliano, ese que hasta el momento estaba guardado bajo llave, encubierto con capas y capas de conjuros inquebrantables. «Rita», esa niña que debuta ficcionalmente en la literatura de su padre, incluso antes de haber nacido - «"Estoy embaraza- 
da", dijo, en su perfecto inglés, Tellas»-, es la puerta entreabierta, la puerta mal cerrada, la puerta-ventana a la que se le ha corrido por descuido la cortina black out (Pauls, 1994, p. 114).

Choco con mi hija frente a la puerta del baño: los dos pretendemos entrar al mismo tiempo. Bosteza; sus ojeras me alarman. "Me quedé hasta tarde leyendo Zoo loco", me explica. Sentada en el borde de la bañadera, con los pies descalzos suspendidos en el aire, me mira mientras me afeito. Tiene la boca abierta, como si asistiera a un prodigio o a un ritual de una tribu exótica. Mi ex mujer solía hacer lo mismo. Decía que mirarme mientras me afeitaba le hacía creer que estaba cerca de descifrar el enigma de ser hombre. La masculinidad solo puede ser un don, y un don que solo conceden las mujeres. Se me llenan los ojos de lágrimas; trago un poco de llanto mezclado con espuma de afeitar, una especie de licor de menta casero que me hace toser hasta las arcadas. Aprovecho el acceso de tos para disimular el llanto delante de mi hija. (Pauls, 2006b, p. 106)

Rita ha descubierto el piropo. "lindo" me dice cuando, después de ponerla a dormir, me estoy yendo de la pieza. "hermoso", "te extraño hasta el cielo y las estrellas", etc. lo nuevo es el momento en que me lo dice: cuando estoy desapareciendo. es la esencia misma del piropo: dejar caer una palabra de amor o de deseo, no apuntar con ella a alguien sino lanzarla en su dirección sabiendo que se perderá, como los hombres lanzan sus piropos en la calle ante una mujer que pasa. Rita sigue hablándome incluso cuando ya estoy fuera del cuarto y he cerrado la puerta. entonces arroja sus piropos en voz alta, como ese grito un poco desalentado que un hombre arroja desde un auto a una mujer que se aleja en dirección contraria. El piropo como celebración de la imposibilidad. (Pauls, 2006c, p. 13)

Rita me propone jugar "a los enamorados". aparece en el living vestida como una prostituta (pollera de cuando tenía dos años, los zapatos de v. de charol rojo y plataforma, cartera de charol rojo, remera sobre remera, etc.) y se derrama, literalmente, en el bkf mientras me mira entrecerrando los ojos. "vos decidís las reglas, papi”. pongo música, entro fingiendo no conocerla, una especie de bar: me acodo a un estante de la biblioteca como si fuera una barra, pido un trago, "la descubro", voy a sentarme a su lado, unas líneas de diálogo pueriles, ella casi no habla, solo frunce los labios y se mece, como flameando, hasta que me inclino sobre ella y le susurro: "¿querés ser mi novia?" y ella, muy rápido: "lamentablemente ya tengo novio". (p. 14)
Esterilizados de los gérmenes que infectan habitualmente su desempeño intimista (elegancia estilística, referencias librescas, elucubración ensayística, alteración de los nombres reales, etc.), estos momentos, si bien pocos, si bien cortos, si bien opacados o directamente segregados de la consideración crítica, son claves a la hora de analizar la performance autobiográfica de Pauls. En primer lugar, porque nos exige moderar algunas de las afirmaciones articuladas aquí: no todo es simulación en el espectáculo que Pauls monta alrededor de su vida personal. No todo es puramente ficcional, impostación, engaño, juego de máscaras. No todo está planeado, supervisado, debidamente controlado por su vocación de trapacero. Hay excepciones, pequeñas anormalidades, zonas-ciénaga donde la temperatura cambia, la tensión interpretativa se modifica, en el que al llegar uno siente que debe parar, volver a leer, quedarse un buen rato allí, inspeccionando ese tiempo dubitativo que se acaba de abrir. Y en segundo lugar, porque estas escenas privadas, al dejarnos arrimar nuestras narices para verlo todo más de cerca, nos revelan el problema general, o más bien íntimo, que conecta de principio a fin los textos que integran este trabajo, uno que siempre estuvo a la vista, desvestido ante nuestros ojos -como la carta robada en el cuento de Poe- y que, por estar demasiado ensimismados en 
tratar de adivinar los trucos de magia del dandi, ignoramos por completo: la paternidad.

La misión de cuidado, complicidad y modelo de «primer hombre» a la que Pauls se apresta con su hija ¿no es, acaso, aquello que provoca el agujero negro que nos permite, además de ingresar al orden de lo privado, entrever la dimensión indecible de lo íntimo? ¿No es este estado -condición o función- el punto ciego, el talón de Aquiles, la kryptonita del dandi Pauls? ¿Y si las escenas domésticas con Rita, dicho de otra manera, antes que leerse al pie de la letra, tal cual están escritas, debieran leerse subrepticiamente como síntoma de otro tipo de vínculo paternal, aquel que enlaza intimamente a Pauls con su padre Axel?

\section{Tercer acto: Axel}

Axel, ese hombre que le sostiene los pies al niño rubio en la tapa de La vida descalzo, el único, por lo demás, que logra sacarle una sonrisa; es, y en subrayado, el callejón sin salida de este desarrollo, el paraje que nos obliga inexcusablemente a volver sobre nuestros pasos. Si no lo hemos nombrado hasta ahora, si hemos omitido sostenidamente su nombre durante todo este tiempo, es porque quisimos dar cuenta de hasta qué punto una lectura de su material autobiográfico resulta insuficiente, por no decir equívoca, sin una perspectiva que interrogue la serie protagonizada por «Axel», piedra de toque a nuestro entender de lo que Pauls no puede (pero quiere) decir.

Pauls, el niño y el adulto Pauls, establece una relación profunda, de deuda y gratitud, pero sobre todo de inmensa fecundidad con su padre. Fecundidad, esto es: como impulso creativo, destinado a abastecer la imaginación literaria de su hijo, $\mathrm{y}$ como impulso íntimo, alojado como insistencia en los vestigios, hiatos, intervalos o hendiduras de lo escrito. El primero, usufructuando indistintamente el uniforme de «padre», no es otro que el «Axel» literario que circula a diferentes velocidades por la autopista ficcional de su hijo; ese mismo que, pervertido desde todos los ángulos posibles -Axel como suegro conspirador (El pasado), divorciado profesional (Historia del llanto), moroso incobrable ("Historia clínica"), rey de los pelados (Historia del pelo), ludópata descarriado (Historia del dinero), entre miles y miles de oficios e identidades inciertas- se alza como un personaje de comedia, uno claroscuro o directamente contradictorio que se mece todo el tiempo entre la infamia y la indulgencia, la inmoralidad y la humanidad, la grandeza y la ignominia. El segundo, por su lado, es el «Axel» más legítimo o más genuino, la prueba fundamen- tal, mejor dicho, que tiene este razonamiento para autentificar como verdaderos a los diarios de Princeton y de Berlín, ambos recopilados en Temas lentos (2012). Estos textos son piezas únicas, y lo son no por la calidad de su material vivencial -de ser así, La vida descalzo, con pasajes como el siguiente, ganaría sin pestañar el trofeo a «mejor pasaje autobiográfico»: «las piernas me temblaban y mi padre -última ofrenda de una noche de gloria, como por otra parte todas y cada una de las 28 noches de febrero, cifra, 28, que durante años representó para mí el emblema de la dicha absoluta- me alzaba por las axilas y me llevaba a caballo sobre sus hombros»-, sino por lo que puede entreverse allí: un duelo (2006a, p. 83). Axel muere en octubre de 2009 propiciando en la escritura de su hijo entradas como éstas:

s. me presta un celular, el mismo Nokia for dummies que accedí a usar en buenos aires -dilapidando años de militancia anti celular- hace un par de semanas. compro una tarjeta $(€ 19.99)$, espero un par de horas que se active, forcejeo con algunas frases en alemán $[\ldots]$ y cuando por fin todo parece en orden y decido probarlo llamando a alguien, caigo en el directorio de números archivados de $\mathrm{s}$. y descubro el nombre de mi padre: axel. antes de pensar cualquier cosa, algo piensa en mí vertiginosamente: ¿por qué s. tiene el número de mi 
padre muerto y yo no? llamo, me atiende un contestador automático, no dejo mensaje. no quisiera que mi padre se preocupara por mí. (Pauls, 2012, p. 133)

¿llegaré a escribir alguna vez sobre la muerte de mi padre? pasan los días -ya una semana- y me doy cuenta que no hago más que posponerlo, esperando que se presente 'una ocasión mejor'. siempre la misma idea: la pereza. 'tendría tanto que decir...' ¿y si en realidad no tengo nada? tendría mucho que contar, pero ¿decir? y cuando pienso en eso me desanimo, como si 'contar', cuando se muere tu padre, fuera una frivolidad o una coartada que solo te permiten una cosa: evitar el horror de no tener nada que decir. lo mismo con berlín: yo buscando, disimulando porque me doy cuenta y me avergüenza un poco- pero buscando el momento preciso en que todo se anudará: mi padre, su infancia en berlín, mi relación con la cultura alemana, max \& moritz, mi muy tardío desembarco en este lugar, mi abuela judía, el exilio, mi resistencia a aprender alemán, las sospechas sobre la etapa alemana de mis abuelos, las mitologías que envuelven su partida, mi relación con la música electrónica de colonia, con el alemán que 'no tiene sentido'... y no pasa nada. Nada (p. 315)

cada tanto me asalta la urgencia: ¡tengo que llamar a mi padre! y en ese mismo mo- mento me doy cuenta de que está muerto. (p. 316)

días opacos. no me cuesta levantarme de la cama, pero media hora después, cuando hice el desayuno y está todo en la mesa, me dejo caer en una silla y descubro que no tengo fuerzas para ponerle manteca a la tostada. y están esas ráfagas traidoras que me asaltan de improviso, en medio de un momento de alegría, por ejemplo, o de completa despreocupación, y me despellejan vivo de tristeza. pienso mucho en el tenis, que más que un deporte, en la relación con mi padre, que fue el que me enseñó a jugar, era casi un modelo de lazo, una forma privilegiada de interlocución: había que pelotear, es decir: estar ahí para devolverle al otro lo que el otro hubiera dado, no importa lo que fuera. ahora no hay devolución. (pp. 317-318)

Sin el amparo de la frase, la cita ilustrada y la cavilación ensayística, estos fragmentos están, como quien dice, en carne viva: ya no puede, sueltamente, aseverarse que han sido escritos para salir del paso. Tampoco que forman parte de su caterva de argucias de su repertorio dandi. Nada de eso. La pretensión aquí está puesta en la verdad y no en la impostura: el yo que se confiesa, aliterado en el pronombre posesivo «mi» $-m i$ padre, $m i$ relación con la cultura alemana, mi muy tardío desembarco en este lugar, mi abuela judía, el exilio, $m i$ resistencia a aprender alemán, mi relación con la música electrónica de colonia-, es un yo fuera del escenario, que se encuentra abatido por la tristeza, un yo, en definitiva, que ha bajado la guardia y que por ello se lo ve sin maquillaje, más traslúcido, menos público y más íntimo.

Dicho esto, estamos en condiciones, ahora sí, de atender -un poco avergonzados- el llamado de Alberto Giordano: si, tal y como nos advierte en varias de sus intervenciones, es justamente allí, en lo que entredicen los procesos de autofiguración, en el que puede leerse la insistencia de ciertos impulsos íntimos («los ejercicios egotistas suelen convertirse en ocasión para que los escritores se sometan, lo sepan o no, lo quieran o no, a la prueba de lo impersonal y lo desconocido»): ¿no es la inclinación a identificarse constantemente con la imagen de niño y discípulo el lugar ideal para meter la nariz y olfatear, como un sabueso, la estela de algo que quiere pero no puede decirse? Dicho de otro modo: ¿no es Axel, expropiándonos de la formulación de Giordano, el afecto insumiso «que ejerce secretamente [presión] sobre la trama de sus discursos autocelebratorios, dotándolos de una intensidad imprevista»? (Giordano, 2013, p. 2). Axel el eslabón perdido de esta serie, aquello que le da un sentido ya no literario sino personal a su 
revisitación a la infancia. Es, digámoslo de una vez, aquel que convierte en hijo al niño rubio: ¿cuántas veces lo alaba, lo encomia, lo ensalza como a un semidios en La vida descalzo? ¿Cuántas páginas enteras, bloques llenos de sentido, le dedica en Historia del dinero? ¿Cuántas veces cuenta que sus padres están divorciados y que los febreros con su padre son infinitamente superiores a los eneros con su madre? ¿Cuántas veces llora, frente a él, en Historia del llanto, y cuántas veces llora, sin él, en sus diarios? Quizás una forma de leer esta trilogía, además de sus lecturas oficiales y propiamente literarias, sea aquella que la imagine como un pago, un desembolso o liquidación de la deuda que él, en tanto hijo agradecido y no parricida, contrae con su padre. De igual modo, sus monerías, ridículos y necedades podrían subliminalmente leerse, a la luz de lo recién arrojado, como figuraciones de lo que ocurre cuando él, no importa si ya adulto o no, queda huérfano en la playa, en la calle, en el mundo, en la vida. Quererse hijo, querer sostener, por otros medios, valiéndose de otros recursos, el vínculo forjado en el paraíso perdido de la niñez: tal es, palabras más, palabras menos, el deseo que resuena y hace temblar la superficie de estos textos.

La autoconstrucción de un autor es siempre un acto retrospectivo: su alumbramiento nunca ocurre en tiempo y forma, sino que, luego de aprender a caminar y valerse por sí mismo -luego de levantar una obra lo suficientemente avezada para tornar su genealogía un problema de interés literario-, el escritor vuelve sobre sus pasos y revisita los escombros de su pasado. Salvo que, más que una sala de parto, antes que los archiveros atiborrados del registro civil, lo que recorre este excursionista del tiempo es la escena de un crimen: muerta la persona, perdido para siempre el pretérito preliterario, el autor (re)lee su propia vida en busca de un rostro. Y es ahí, en ese acto de antemano estéril (la exhumación impoluta de su materia fósil), cuando el escritor confecciona su propio identikit. Uno a gusto, claro está, porque lo que importa no es encontrar el verdadero cadáver - eso que, orgullosos, los anticuarios 1lamarían «la verdad del sujeto»-, sino algo más rentable, más acorde al presente que lo interpela: una credencial idónea, exenta de ignominias, para proyectarse en lo público.

Las incursiones egotistas que acabamos de incursionar, dicho de otro modo, dejan a las claras la especie a la que Pauls pertenece y aquella que milita con fervor: una que, con libertad absoluta, concibe a la «vida» no como una entidad sacra a la que se le debe rendir culto únicamente con el folklore de la verdad (el afán de ella), sino, más bien, como un material más para ser leído, esto es, disponible para ser labrado, trocado, pervertido en el laboratorio de la escritura. La vida, para un dandy como lo es Pauls, no puede dejarse al arbitrio de los valores que cimentan, en su sentido más vulgar, la práctica de la confidencia (léase búsqueda de autenticidad, franqueza, espontaneidad); lejos de presentársele como un stock de testimonios fidedignos, debidamente procesados e inconmovibles del que sólo se espera un único uso (su reproducción), la vida se monta en Pauls como un teatro o una película: pura actuación, montaje, performance, acomodada para ser travestida -interferida-, según diferentes máscaras (la del niño bibliófilo, cinéfilo y autista, la del adulto idiota y extraviado, etc.). De allí que el antifaz -el rol, el papel- de «hijo» sea tan significativo en toda esta serie, el punto axial de la novela familiar que acabamos de explorar: al intentar ponérselo se da cuenta que no puede, que es demasiado pesado, que es alérgico a su material y que lo que se proponía a hacer no sólo ya es historia pasada sino que, a contrario sensu, todo su sistema inmunológico ha quedado a merced del único virus capaz de desmoronarlo por completo: la verdad. 


\section{Referencias}

Aira, C. (2001). Cumpleaños. Buenos Aires: Random House.

Catelli, N. (2007). En la era de la intimidad. Seguido de: El espacio autobiográfico. Rosario: Beatriz Viterbo Editora.

Cohen, S. (2012). Los avatares del yo. Literatura argentina en primera persona a partir de 1990 (Tesis doctoral, Rutgers, The State University of New Jersey, New Jersey). Recuperado de https://bit. ly/2K9uAsk

Domínguez, N. (2012). Errancias de una forma: los diarios de escritores. Zama, 4(4), 99-104. Recuperado de http://revistascientificas.filo.uba.ar/index.php/zama/article/view/621

Falco, M. (29 de septiembre de 2018). Alan Pauls: "No soporto el lenguaje inclusivo, van a pasar sobre mi cadáver antes de que yo diga todes”. Infobae. Recuperado de https://bit.ly/34oGYeA

Giordano, A. (2006). Una profesión de fe. En Una posibilidad de vida. Escrituras íntimas (pp. 195-213). Rosario: Beatriz Viterbo Editora.

Giordano, A. (2008). El giro autobiográfico de la literatura argentina actual. Buenos Aires: Mansalva.

Giordano, A. (2013). Autoficción: entre literatura y vida. Boletín del Centro de Estudios de Teoría y Crítica Literaria, (17), 1-20. Recuperado de https://www.cetycli.org/cboletines/cd98f00b20-albertogiordano17.pdf

Giordano, A. (2017). Notas sobre diarios de escritores. Alea: Estudios Neolatinos, 9(3), 703-713. Recuperado de https://www.redalyc.org/pdf/330/33053320016.pdf

Laurent, P. (2010). Acopio de compulsiones. Fragmentos de una conversación con Alan Pauls. Revista Letral, (5), 116-130. Recuperado de https://dialnet.unirioja.es/servlet/articulo? codigo=5370579

Kohan, M. y Laera, A. (2001). Variaciones sobre la crítica. Entrevista a Alan Pauls. Milpalabras, (1), 63-72.

Link, D. (17 de julio de 2006). Libros recibidos. Linkillo (cosas mías) [Blog]. Recuperado de http:// linkillo.blogspot.com.ar/2006/07/libros-recibidos.html

Link, D. (4 de agosto de 2007). La imaginación intimista. Linkillo (cosas mías) [Blog]. Recuperado de http://linkillo.blogspot.com.ar/2007/08/la-imaginacin-intimista.html 
Montes-Bradley, E. (Prod.) y Guebel, D. (Dir.). (2005). Si yo fuera realmente libre: Alan Pauls. Buenos Aires: Contrakultura films / Heritage Film Project. Recuperado de https://vimeo.com/99396320

Orecchia Havas, T. (2013). Apuntes sobre el territorio y la creación: vidas de Alan Pauls. Cuadernos LÍRICO, (9), 1-18. Doi: https://doi.org/10.4000/lirico.1153

Pardo, J. L. (1996). La intimidad. Valencia: Pre-Textos.

Pauls, A. (1993). La retrospectiva intermitente. Cuadernos hispanoamericanos, (517-519), 470-474. Recuperado de https://bit.ly/2KBbDyy

Pauls, A. (1994). Wasabi. Barcelona: Anagrama.

Pauls, A. (1996). Prólogo. Las banderas del célibe. En Cómo se escribe el diario íntimo (pp. 1-14). Buenos Aires: El ateneo.

Pauls, A. (2000). El factor Borges. Barcelona: Anagrama.

Pauls, A. (2002). Interminable. Un diario íntimo. Nueve perros, 2(2/3), 42-50.

Pauls, A. (2006a). La vida descalzo. Buenos Aires: Sudamericana.

Pauls, A. (2006b). Mi vida como hombre. En M. S. Cristoff (comp.), Idea crónica. Literatura de no ficción iberoamericana (pp. 101-116). Rosario: Beatriz Viterbo Editora.

Pauls, A. (2006c). Un diario (fragmentos). En C. Szperling y M. Anghileri (comp.), Confesionario. Historia de mi vida privada (pp. 11-18). Buenos Aires: Libro del Rojas.

Pauls, A. (2010). Filcar. Un diario íntimo. En Buenos Aires: la ciudad como un plano. Crónicas y relatos (pp. 155-171). Buenos Aires: La bestia equilátera.

Pauls, A. (20 de febrero de 2011a). Historia clínica. Un diario íntimo. Página/12. Recuperado de https:/www.pagina12.com.ar/diario/verano12/23-162711-2011-02-20.html

Pauls, A. (2011b). Mal de tiempo (prólogo). En F. S. Fitzgerald, El Crack-Up (pp. 9-22). Buenos Aires: El Crack-Up. 
Pauls, A. (2 de octubre de 2011c). La ley del mercado. Página/12. Recuperado de: https://www. pagina12.com.ar/diario/suplementos/radar/9-7373-2011-10-02.html

Pauls, A. (2012). Temas lentos. Selección y edición de Leila Guerriero. Santiago de Chile: Universidad Diego Portales.

Pauls, A. (2013). Fuego artificial (prólogo). En H. Balzac, C. Baudelaire y J. A. Barbey D'aurevilly, El gran libro del dandismo (pp. 9-24). Buenos Aires: Mardulce Editora.

Pauls, A. (2018). Prólogo. En Roland Barthes por Roland Barthes (pp. 7-17). Buenos Aires: Eterna Cadencia.

Pérez Zabala, V. (19 de febrero de 2017). Alan Pauls: "la literatura que a mí me gusta no tiene nada que ver con contar historias. La Nación. Recuperado de https://www.lanacion.com. ar/lifestyle/alanpaulslnr-nid1984534/

Rodríguez Montiel, E. (2019). La incomodidad del dandi. Sobre Historia del llanto de Alan Pauls. Chuy. Revista de Estudios Literarios Latinoamericanos, 6(7), 139-162. Recuperado de http://revistas.untref.edu.ar/index.php/chuy/article/view/317/407

Sarlo, B. (2005). Tiempo pasado. Cultura de la memoria y giro subjetivo. Una discusión. Buenos Aires: Siglo XXI.

Tizón, H., Martini, J. C. y Pauls, A. (1995). Experiencia y lenguaje. I. Punto de vista, 18(51), 1-4. Recuperado de http://www.bazaramericano.com/media/punto/coleccion/revistasPDF/51.pdf

Villanueva, G. (2019). La felicidad en La vida descalzo (2006) e Historia del llanto (2007) de Alan Pauls. Crisol, (4), 1-14. Recuperado de http://crisol.parisnanterre.fr/index.php/ crisol/article/view/71/82

Zambrano, M. (1995). La confesión: género literario (3. ${ }^{\mathrm{a}}$ ed.). Madrid: Siruela. 